\title{
How Advertising Reflect Culture and Values: A Qualitative Analysis Study
}

\author{
Reneh Abokhoza \\ Assistant professor - Al Falah University-UAE \\ Sherehan Hamdalla Mohamed \\ Lecturer - British University -EGYPT \\ Dr. Sumit Narula \\ Director and Associate Professor, Amity School of Communication \\ Amity University Madhya Pradesh, Gwalior
}

\begin{abstract}
A successful advertising campaign is linked directly to how its perceived by different societies. This has led international companies to structure their advertising campaigns according to the culture of the society they are targeting. Hence, it is critical to have a strong understanding of the general attitude and characteristics of that particular society in order to create a message that resonates with the needs of its individuals. This study aims to identify the impact of advertising campaigns in stimulating cultural communication. A comparative analysis between Pepsi's ads from Egypt and Saudi Arabia, which were presented at the same time, shows that different advertising strategies were employed to effectively communicate its product in these two markets. The analysis revealed that Pepsi's Advertisement in Saudi Arabia used shared values to preserve the national identity within the message of the advertisement to connect with consumers, while Pepsi's Advertisement in Egypt was entertaining in nature with little to no cultural value. Moreover, special effects were used in the Advertisement from Saudi Arabia, while the Advertisement from Egypt relied heavily on uncreative elements, mainly funny scenarios, and scenes from old Egyptian songs and movies. The analysis of both ads confirms that Pepsi's advertising campaign in Saudi Arabia was more aware of the social and cultural values of the society as oppose to the campaign in Egypt.
\end{abstract}

Keywords: Advertising - Community Values - Culture- Communication- Social Responsibility.

\section{Introduction:}

Advertising is one of the most effective and efficient forms of outbound media not only because businesses can disseminate their message on a variety of platforms whether it is done through television, radio or social media platforms, but also because of the role it plays in increasing profitability by helping increase sales and revenue. In the modern world businesses, competing globally and serving international customers has become a fact of life for many companies that hope to stay ahead of their competition. This has urged companies to look for innovative and creative ways to promote their products in the global market and design campaigns that take into consideration cultural differences and tap into consumers' beliefs and shared values

\section{The Power of Advertising}

The role and functions of advertising in the new global economy of the 21st Century is vital in developing local businesses and enabling them to face the competition of other companies globally. Hence, it is crucial for international companies to develop their marketing strategies that resonate deeply with the culture and values of the targeted society. In today's business environment, the advertising and marketing industry is constantly evolving in terms of market size, quality and content and must keep abreast of technological advances to come up with creative advertising and marketing concepts to compete locally and internationally.

With a successful advertising campaign, companies can gain an advantage over their competition. Hence, it is essential for any campaign to consider the different perspectives on community issues, focus on the content and harness technological advances to create a creative concept. However, advertising is no longer about persuasion so much as creating a positive experience that will influence the consumers over the longer-term. In fact, many critics of 
advertising believe that advertising has a profound impact on consumerism and cultural values. Critics believe that advertisers promulgate superficial consumerism by creating "false consciousness" and "manipulate the symbols that serve as social fabric of human association (Wharton, 2013)

\section{Advertising and Cultural Values}

The impact of advertising is no longer limited and can have both positive and negative effects on society to a certain extent depending on the content of the message and how it resonate with the values, norms and culture of a specific society. Choosing the right message to promote is critical for a successful advertising as it can influence the way consumers live their lives, perceive their needs and wants and whether and how they think about themselves especially when it is promoted through various media channels. Also, Consumers who are seeking social improvement are easily influenced with advertisements and try to impersonate what they see for self-satisfaction.

Likewise, the type of language used in advertisements to convey specific messages has a great impact on the consumer. There are different signs of verbal and nonverbal communication advertisers employ to communicate their messages in their ads. As language is the verbal symbol, advertisers always keep in mind the emotive power of the words they use. Non-verbal symbols include shapes, colors, and facial and body messages. Of course there are other numerous symbols that carry specific messages depending on how they are used in recreating reality such as using makeup, garments, and creating the characters in the ad. Images and music integrated in ads also play a role in catapulting a distinct emotional connection. Consistent imagery in ads is a useful way to deliver the message, to increase customer engagement, and to create value and cultural connection while building a brand foundation. Also, companies around the world are incorporating social responsibility into their overall business strategy.

In sum, it is crucial for companies to incorporate these elements into their ads to enhance their relationships with the customers and communities they are targeting and improve their image which in turn can lead to increasing sales and profits.
The substance of the advertising, its structure and its verifiable incentive in the content and picture reflect social qualities, that might be in the administration of the way of life of society, or an apparatus for committing intriguing societies to the utilization of open images in the plan of the publicizing message and pursue the methods for affecting the buyer and its way of life and embracing unpredictable implies that assistance to expand customer taste. The best and nearest publicizing message for global advertising techniques while saving Arabic language, culture, and choosing the proper occasions and stories appropriate for Arab culture. Middle East satellite stations can add to the transmission of new sorts of business notices that are in accordance with Arab esteems and are unmistakable. Commercial advertisements go past financial measurements to incorporate social measurements that might be progressively significant and even more striking.

\section{Literature Review}

Looking broadly at earlier studies, it appears that advertising plays a significant role in reflecting communities' shared values and shaping societies. For instance, one of the studies explored the utilization of broad communications to explicitly promote a social change that debilitated societies and replaced their culture with a pseudo-culture. Adorno's hypothesis of pseudo-culture, was employed to analyze how political ideologies can create social change by using mass-mediated Advertisement images. The study applied a semiotic and content analysis to analyze print ads for a period of 48 years. The researchers identified five noteworthy themes underlying pseudo-culture formation and the advertising strategies used to support them. Furthermore, it recognized four noteworthy tools used in pseudo-culture formation and revealed how pseudo-cultures can be created, indorsed, and eliminated (Yazdanparast, 2018).

A study done by Noel JK investigated factors that can influence the appeal (i.e. source appeal, informational appeal and emotional appeal) of a social media Advertisement and found that the main factors are; changes made to the content of the ad, user engagement values associated with the Advertisement and user-generated comments (UGCs) associated with the ad. Noel investigated the appeal of 
beer advertising on Facebook and found that it can be largely determined by Advertisement content. When emotional appeal is used to a great extent in advertising by non-compliant advertising, the Advertisement is more likely to be remembered and to influence future drinking occasions (Noel, 2018).

On the other hand, other studies examined the impact culture-related values have on endorsing the male and female gender role stereotyping in advertising. One of these studies was carried out on respondents from Sweden and Germany to test the impact of respondents' masculinity, power distance, assertiveness values and feminine role orientation on Advertisement attitudes and brand attitudes. The study found that perceived stereotyping has a positive impact on the Advertisement and brand attitude, and this effect is enhanced for more masculine, more power distant, more assertive and less feminine-role oriented individuals. While there was a negative response to perceived female stereotyping in comparison to male stereotyping, and this applies particularly to individuals who are more power distant and assertive. (De Meulenaer, 2017)

After investigating the content of advertisements published in Iranian magazines, Nazari proposed strategies to achieve effectiveness in commercial advertising in Iranian Social and cultural magazines. Furthermore, Nazari in this study identified the effects of advertisements that conflicted with social and cultural values. The study found that lack of definition and culture for advertisements, lack of advertising specialists, stereotyping, lack of professional organizations to analyze and examine advertisements have been recognized as the most important damages to Iranian magazines. With respect to the outcomes of the performance analysis of the magazines that were under study in terms of advertising, it was found that cultural and social values of Iranian community were not depicted and the content was based on beautiful values (Nazari, 2017) .

After examining American movie trailers, car ads and commercials of fast food chains, $\mathrm{Su}$ Jiangli concluded that American companies in China do not only advertise their products or services but also promote the American culture, values and way of life through advertising and in fact have an impact on Chinese teenagers and middle class. Jiangli believes that they represent important part of American soft power and can actually meet the three dimensions of public diplomacy: daily communication, strategic communication and building lasting relationship. Moreover, Jiangli maintain that they have the ability to transform the abstract soft power of culture values to something more visible and tangible and because they can directly affect the lives of Chinese people, the influence is pervasive which could present a challenge to protecting the traditional Chinese culture and values (Jiangli, 2015)

N. Anido Freire analyzed advertisements for two luxury brands that display identity values of luxury using emiotic and rhetoric analysis. The study identified the semic richness of discursive content of symbolic images and identity narratives of each luxury brand and their implications. Freire concluded that major luxury houses' presence and strength lie in the coherence they apply globally in terms of creation, products, narratives and advertisings which reinforces their brand image and attract more loyal customers. (Freire, 2014)

\section{Aim of Study}

This study aims to identify the role advertising plays in cultural communication, in preserving the cultural identity of any society and in spreading cultural values of other societies to preserve their originality. This is done by analyzing the content of two advertisements, and explore to what degree companies are keen to link their brand with different cultural and social values.

\section{Study Questions}

This study instigates the social responsibility of Commercial Advertisements and attempts to answer the following question: to what extent does the commercial advertising reflects cultural values?

\section{Data and Sample}

The study examines two advertisements PepsiCo has launched in Egypt and Saudi Arabia as part of their 70th anniversary celebrations. :

1. Advertisement in Egypt as seen on 15 January 2018 with the slogan \#Lovely, incorporated famous scenes from Egyptian movies, and songs 
2. Advertisement in Saudi Arabia as seen on 27 January 2018 with the slogan \#I am Saudi, included scenes with sentences that mirror the values and morals of the Saudi culture.

\section{Methodologies}

Interpretive Paradigm was employed in this study to understand the role advertising plays in reflecting cultural value. Conclusions were drawn after a thorough analysis two ads from two countries were chosen for an international company to show how advertisers followed different advertising strategies for the two countries.

1-Analysis Tool: the analysis tool was validated by experts (Dr.Hassan Mostafa, dean of mass communication, al falah university, UAE Dr.khalid Henidi, associate professor, mass communication, AL falah University, UAE, Dr .Amany Albert, associate professor, head of public relations department, Beni Suef University, Egypt )before it was employed in the study to ensure the validity and reliability of the results. It was based on a set of criteria to measure the differences between the ads. The study tool was designed to fit the qualitative analysis for both of the advertisements; the first Advertisement was launched in Egypt with the slogan \#Lovely and the second in Saudi Arabia with the slogan \#I am Saudi. The tool consists of the following elements:
1. Scenes
2. Objectivity.
3. Colors.
4. Characters
5. Attraction
6. Clarity of the message.
7. Target audience.
8. Community responsibility
9. .customs
10. Values
11. Slogan
12. Language

2-Comparative Method: So as to recognize the distinctions and similitudes given by Pepsi in Egypt and Saudi Arabia and the degree to which the substance of the advertisement is identified with the way of life and estimations of the nation submitted for it. The study compared two of Pepsi's ads in Saudi Arabia and Egypt to find the similarities and differences in the content and how relatable the ads are to the Egyptian and Saudi cultures.

\section{Results \& Disussion}

The researchers used the qualitative method to compare between the two ads to show how to advertise for a product and whether Pepsi was successful in present a specific image of Arabs and their culture. To the following factors were taken into account to compare between the content of both ads and the results are:

\section{Sequence}

Pepsi's Advertisement in Egypt: Pepsi's commercial in Egypt brings masterworks to life by taking the audience through a number of reenacted iconic scenes from classical films and songs. The Advertisement takes the audience through six scenes for 1.30 minutes. It opens with a scene of farmers singing, a song taken from the old movie "Al-Zawja Althaniya" for the Egyptian stars Souad Hosni and Shokry Sarhan, followed by a scene in a villa where a scene recreated from the Egyptian film "Rod qalbi". The Advertisement progresses to another scene recreated from the movie "khally ballak men zouzou" which was released in 1972. A song for the famous Egyptian singer Amr Diab is also featured in the Advertisement "homdalla ala salama", followed by a recreated scene from the video clip "Ya liel" by the Egyptian band Wama. Cutting to final scene, s actors are singing and dancing when finally a can labelled Pepsi appears in the middle of the screen and the design of the can keeps changing to show how it has evolved and changed over the years till it stops at the latest design (figure 1).

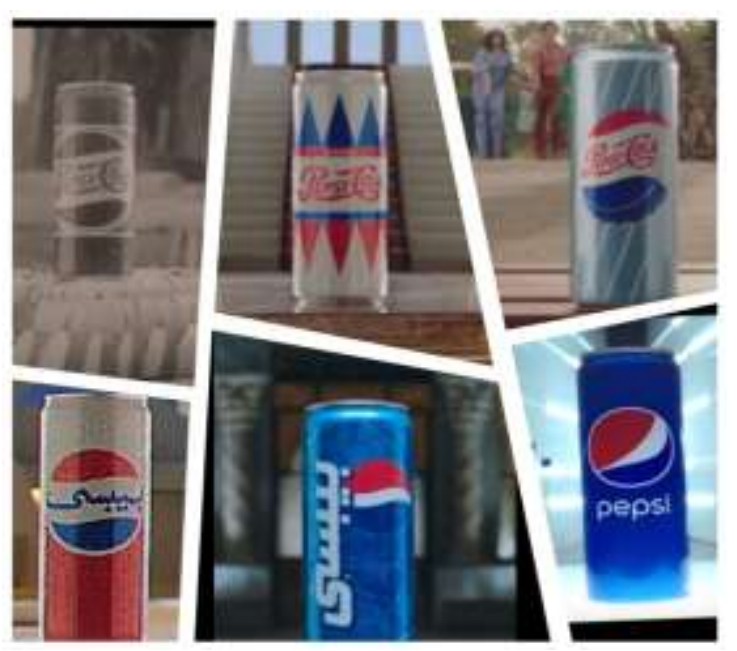

Figure 1 


\section{Designs of Pepsi can in Egypt}

The Advertisement wraps with the ending title: Lovely (figure 2). The message Pepsi is trying to send across with this Advertisement is that while things have changed in the last 70 years, Pepsi's great taste remains the same. The Advertisement successfully strikes an instant connection with the audience with its beauty, simplicity and by creating a feeling of nostalgia and a sense of joy. By injecting humor and joy, the Advertisement successful captivates the audience from the opening to closing scenes.

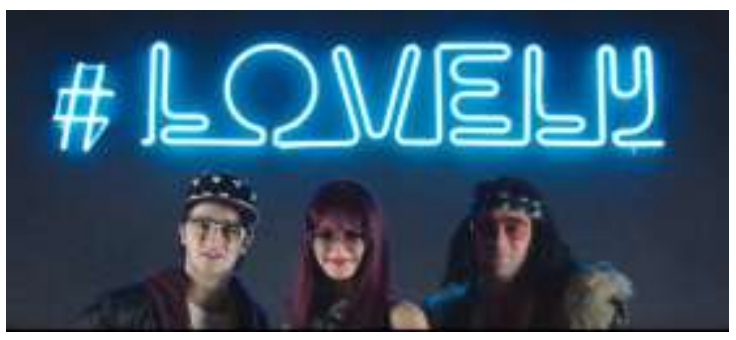

Figure 2

Pepsi Advertisement Egypt with an end title

\section{Pepsi's Advertisement in Saudi Arabia:}

The Advertisement opens with a view for $\mathrm{Al}$ Faisaliyah tower in Riyadh and zooms in to an apartment where a man is seen sitting on a sofa who seems to be concerned about something. A narrator then says "something inside me tells me that today is going to be a great day" "when suddenly the man's face changes to another man's. Then the man stands and walks away from the sofa and a voice over say "something inside me wants me to learn and know more." He wears a Qalansuwa, borderless white hat, then he stands in front of a window and looks out when his face changes once more and the voice over says "it makes me feel like I haven't achieved anything yet." . The man then puts his hand on his face and he changes again to another person and the voice over says "something inside of me wants me to improve." he then walks towards a hanger to pick a head scarf "Ghutrah" and the face changes again and we hear the voice over saying " it tells me don't listen to anyone that makes you doubt tomorrow." The face changes again and the man wears the Ghutrah and the voiceover says "because what's inside of me says that the sky is the limit" he stands infront of a mirror and the face changes again. Voice over then says "every successful person is found in you" the man then walks towards a door and opens it with the voiceover saying "because inside of you is something great that can make anything possible." The face changes again but this time it is a woman wearing Abaia, the traditional dress for Saudi women. The woman's face changes also to another woman's face. Cutting to the last scene, doors open and faces change repeatedly, then the voiceover says "on the inside, you are Saudi." And the Advertisement ends with the ending title "Generations pass, but our core remains the same." And just like the Advertisement in Egypt, the design of the can keeps changing to show how it has evolved and changed over the years (figure3). The message in this Advertisement is the same as the message of the Advertisement in Egypt however, this Advertisement relies heavily on Saudi's strong sense of nationalism and patriotism by enforcing a sense of national and social unity

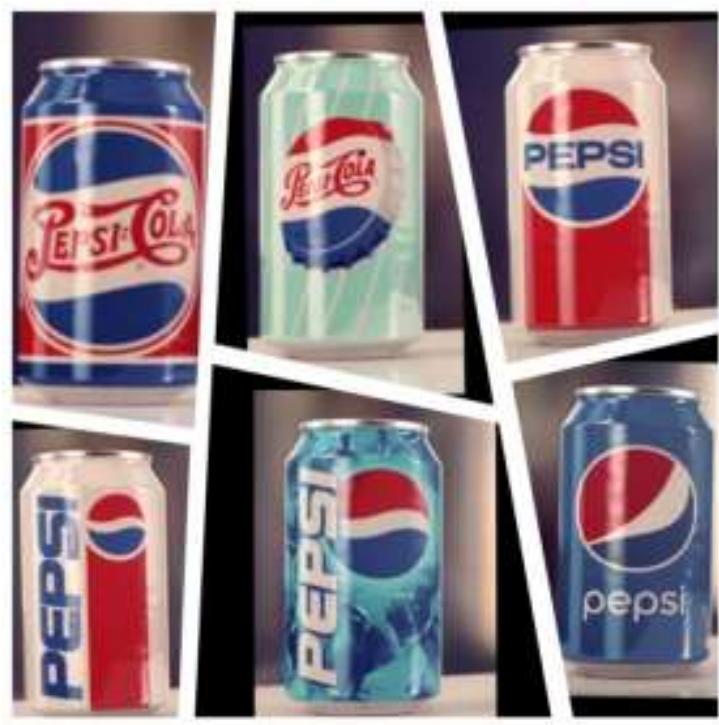

Figure 3

\section{Designs of Pepsi can in Saudi Arabia}

\section{2- Objectivity}

Pepsi's Advertisement in Egypt: While the Advertisement is creative, and fun, it does not attempt to foster a sense of national and social unity. It also does not make any connection to the culture or social values of Egypt. The ad, however, highlights how the pop culture in Egypt has evolved over the years to show that Pepsi has evolved too but without compromising its taste.

Pepsi's Advertisement in Saudi Arabia: the message Pepsi is trying to send across with this Advertisement is that despite all the changes Saudi Arabia has gone through, the 
"core" i.e. the culture and tradition remained the same. So is the case with Pepsi; the design of the can changed over the years but the taste did not change.

\section{3- Colors}

Pepsi's Advertisement in Egypt: Color and black-and-white have been used in this Advertisement for symbolic effect. The Advertisement starts with the black-and-white scene to pay homage to the Egyptian classic cinema. Then it changes to color and changes in brightness and contrast as well. The Advertisement successfully uses warm colors to induce a sense of energy, enthusiasm, cheerfulness, and optimism.

Pepsi's Advertisement in Saudi Arabia: this Advertisement on the other hand relies on cold colors that are both bright and dark in the décor to highlight ambitious and hardworking qualities in Saudis and to add subtlety and stability. Warm dark colors are also used in the Advertisement to express Saudi's strong connection to classics, tradition and to show elegance.

\section{4-Characters}

Pepsi's Advertisement in Egypt: the Advertisement features the following young stars who are known for their acting and singing abilities:

Ahmed Malek: plays a funny character. This Advertisement is his second role as a singer and an actor after his role in the movie (Ahwak)

Tara Emad: is a young beautiful actress who is very quiet. She is best known for her roles in cinema and this was her first ad. The character she plays is funny, cheerful and very, energetic.

Mohamed salaam: is a popular comedian who appeared in several comedy movies.

All the stars featured in this Advertisement danced and sang cheerfully to give a sense of joy.

Pepsi's Advertisement in Saudi Arabia: The following stars were featured in the ad:

Muna AbuSulayman: a Saudi activist and cohost of a popular talk show.

Nwaf El Shake and Mohamed Ibrahim Mohamed: are Saudi footballers who play for el Naser.
Qusai khedar: is a Saudi, a singer/songwriter, record producer, rapper, TV host, DJ and first professional Saudi hip hop artist.

Fayez El Malki: is a Saudi, a comedian actor.

Both ads relied on celebrities' endorsement to boost exposure and influence sales. The Saudi Advertisement featured a bigger number of celebrities who are able to reach a bigger number of people through different mediums from both genders and different ages.

\section{5- Attraction}

\section{Pepsi's Advertisement in Egypt}

Attraction and appeal are crucial components to affect consumers and to create interest. Both ads make good use of the following elements:

Colors: both ads make good use of color as a medium of showing the mood of the message , in the first ad, the colors are happy, vibrant and exciting which goes hand in hand with the ad's slogan "Lovely".

Quoted scenes: The Egyptian Advertisement recreates successfully scenes from classical movies and songs in a funny, witty, enjoyable and memorable way.Modernity: although the Advertisement is a nostalgic, sweeping look back at the history of the cinema in Egypt, this tactic has never been used before in Egypt.

\section{Pepsi Saudi Arabia}

Visual effects: This Advertisement uses visual effects to engage viewers, increase popularity and increase the likelihood to purchase. This tactic has never been used before in commercials in Saudi Arabia and the execution was spot-on.

Modernity: By employing special visual effects, celebrities' endorsement and a modern setting, the Advertisement succinctly captures several aspects of modernity. These aspects of modernity are more than just a wow factor they are essential to the story and to creating a positive association with the brand.

Sequence: The smooth transition from one scene to another and the brilliant way the visual effects were used, make it hard for the audience to notice the changes in the faces of the celebrities.

Over all, both commercials draw on attraction and appeal elements.

6- Clarity of message: 
Pepsi's Advertisement in Egypt: While the concept and order of scenes are clear and flow smoothly, the message is not clear until the last scene when a can of Pepsi appears in the middle of the screen and a voice over says that 70 years have passed since the drink was first introduced.Pepsi's Advertisement in Saudi Arabia:The message Pepsi is trying to send across with the visual effects of changing faces of celebrities throughout the commercial, is to show that while people and situations change over time, Pepsi is still as it was first introduced 70 years ago just like the Saudi culture and traditions.

Overall: the idea of the Saudi Advertisement was delivered in a clear and direct way as oppose to Pepsi's Advertisement in Egypt.

\section{7- Targeted audience}

There are a representation of race, gender, lifestyle and overarching themes for different age ranges in both ads.

\section{8- Community responsibility}

Pepsi's Advertisement in Egypt: one of the effective advertising strategies is catering to specific cultural value in their ads of the targeted audience. In this ad, Pepsi displayed the theme of festivity and happiness and customized to appeal to the people in Egypt. While the Advertisement pays tribute to classic cinema and the pop culture, it does not focus on manifesting cultural values, norms or any type of community responsibility.

Pepsi's Advertisement in Saudi Arabia: This Advertisement takes into consideration cultural value, norms and stereotypes of the target audience and the larger culture of Saudi Arabia. Some of the several cultural elements that are used in the Advertisement include distinguished Saudi figures and symbols of public spirit. In fact, the Advertisement shows the different character wearing the national dress, which is a source of pride for all Saudis and highlights the fact that despite globalization the traditional customs of the Kingdom are not affected .It is evident that Pepsi's Advertisement is successful in reflecting culture and values and in turn achieving community responsibility towards the Saudi society.

\section{9- Costumes}

Pepsi's Advertisement in Egypt: Costumes in ads play a key role in telling the story and bringing the characters to life. As the Advertisement pays homage to classical movies and popular songs, costumes in this Advertisement are done to mimic the original costumes that appeared in these masterworks. Just like the can of Pepsi that appear at the end of the Advertisement and changes in color and design, costumes were also employed to show the changes that took place in fashion in Egypt during the last 70 years.

Pepsi's Advertisement in Saudi Arabia: to reflect the Saudi culture, the national dress is seen throughout the ad. The national Saudi dress is also used to highlight the main idea of the ad; time passes but the core remains the same.

\section{0- Value}

Pepsi's Advertisement in Egypt: Pepsi uses in this Advertisement the theme of festivity and happiness by paying tribute to classic cinema and the pop culture. There is no manifestation of cultural values, norms or any type of community responsibility. Nothing in the content of the Advertisement reflects morals, social or religious values.

Pepsi's Advertisement in Saudi Arabia: This ad, on the other hand, takes into consideration cultural values and norms of Saudi Arabia and included symbols of public spirit. In fact, the Advertisement takes a social responsibility to contribute to the Saudi national identity discourse and to install certain traditional values in the young generation in an attractive way.

\section{1- Slogan}

Pepsi's Advertisement in Egypt: The punchline in this Advertisement is \#Lovely. There is no cultural significance behind this punchline, it is simply used to indicate that the taste of Pepsi is loved by all.

Pepsi's Advertisement in Saudi Arabia \#IamSaudi; the slogan clearly serves the message the Advertisement is trying to send across; take pride in your national identity.

12- Language: Although the relation between language and culture is complex, due largely in part to great difficulty in understanding people's cognitive processes when they communicate, they are closely interconnected. (EL MES, 2013) Hence, both ads use the spoken language and accent of the target audience to convey their messages which can 
influence the viewers to buy the product. In terms of word meaning, denotative and connotative meanings are both used in these ads. Connotative meaning represents the various "social overtones, cultural implications, or emotional meanings" associated with the ad. Denotative meaning represents the explicit or common dictionary meaning. For instance, the word "lovely" used throughout the Egyptian Advertisement has denotative and connotative meanings. The denotative meaning of the word is that the taste of the drink is lovely while the connotative meaning is that with Pepsi, the precious and lovely moments are more enjoyable. (Csun.edu, 2019)

\section{Conclusion}

To mark its 70th anniversary PepsiCo launched two ads in Egypt and Saudi Arabia. This study analyzed these ads to understand the impact of these two cultures on making them and found that the Advertisement that targeted consumers in Egypt followed the theme of festivity and happiness while paying homage to classic cinema and pop culture in Egypt. Unlike the Advertisement in Saudi Arabia, it does not focus on manifesting cultural values, norms or any type of community responsibility. In fact, the Saudi Advertisement incorporated several cultural elements such as distinguished Saudi figures and symbols of public spirit. The Saudi

\section{Importance of the Study}

Most of the Studies reflect the role of advertising in presenting cultures quantitatively. The present study takes a qualitatively approach in reflecting the different cultures of different countries. This study illustrates how companies like PepsiCo have been using cultural values in their advertising campaigns taking advantage of its influence on their target audience to boost their sales.

\section{Recommendations}

1- Companies around the world must have strong corporate social responsibility (CSR)

3- Companies should consider incorporating more positive social messages in their ads.

4- Appreciating companies that have strong CSR and use then as model for other companies.

\section{Implications and Suggestions}

Findings of this study highlight the role of advertising in reflecting cultural values. However, it is recommended to expand the research scope to explore how companies can use cultural norms and ethics in their advertising campaigns to ensure its success. Future research could also explore the potential effects of digital advertising on societies.

\begin{tabular}{|c|c|c|}
\hline \multicolumn{3}{|c|}{ Table 1: Variations of Pepsi AD in Egypt \&Saudi Arabia } \\
\hline Criteria & Pepsi's Ad in Egypt & Pepsi's Ad in Saudi Arabia \\
\hline Language & $\begin{array}{l}\text { Simple and direct with no } \\
\text { cultural references. }\end{array}$ & Effective, clear, powerful and encouraging. \\
\hline Target Audience & No specific audience & no specific audience \\
\hline Colors & $\begin{array}{l}\text { Warm colors to induce a sense } \\
\text { of energy, enthusiasm, } \\
\text { cheerfulness, and optimism }\end{array}$ & $\begin{array}{l}\text { Cold colors and warm dark colors to } \\
\text { highlight ambitious and hardworking } \\
\text { qualities in Saudis and to express Saudi's } \\
\text { strong connection to traditions. }\end{array}$ \\
\hline Customs & Colorful and cheerful & Conservative and traditional. \\
\hline $\begin{array}{l}\text { Social } \\
\text { Responsibility and } \\
\text { Value }\end{array}$ & $\begin{array}{l}\text { Does not pay any attention to } \\
\text { community values. }\end{array}$ & $\begin{array}{l}\text { Cultural values and social responsibility are } \\
\text { evident }\end{array}$ \\
\hline Message & Not clear until the last scene & Direct and clear \\
\hline Slogan & Lovely & I am Saudi \\
\hline
\end{tabular}

Advertisement takes a social responsibility to install certain traditional values in the young generation in an attractive way (Table1).

\section{Reference:}

- David ELmes, the relationship between language and culture, National institute of fitness and sports in konoy international Exchange and language education center, 2013,pp 11-15. 
- De Meulenaer, S., Dens, N., De Pelsmacker, P., \& Eisend, M. (2017). How consumers' values influence responses to male and female gender role stereotyping in advertising. International Journal of Advertising, 1-21.

- Freire, N. A. (2014).When luxury advertising adds the identitary values of luxury: A semiotic analysis. Journal of Business Research, 67(12), 2666-2675.

- Hing Cheng, Padimini Patwordhan, One region, two worlds? culture values in Chinese ana Indian T.V Commercials ,Asian Journal of communication vol 20, no 1,2010,p 69-89.

- Jiangli, S. (2015).Advertising American Values and Way of Life: Public Diplomacy and American Companies' Ads in China. Journal of Anthropology and Archaeology, 3(2), 37-47.

- Morris Kalliny, lance Genrtry, Cultural values reflected in Arab and American television, Journal of current issues and research in adveritising , v29,n1 ,2007,p1532.
- Nazari, S. (2017). Pathology of commercial advertising in Iranian Social and Cultural Magazines during 2001-2011. European Online Journal of Natural and Social Sciences: Proceedings, $6(1$ (s)), pp-77.

- Noel, J. K., Babor,T. F., \& Grady, J. J. (2018). Advertising Content, Platform Characteristics and the Appeal of Beer Advertising on a Social Networking Site. Alcohol and Alcoholism.

- Wharton, C. (Ed.). (2013). Advertising as culture. Intellect Books.

- Yazdanparast,A., Naderi,I., Spears, N., \& Fabrize, R. O. (2018). Advertising and Pseudo-Culture: An Analysis of the Changing Portrayal of Women in Print Advertisements. Journal Macromarketing, 0276146718762475.

- Young Sook Moon, Kara Chan. ( 2005). Advertising appeals and culture values in television commercials, journal of international marketing review, 22(1), 48.

- Csun.edu. (2019). [online] Available at: https://www.csun.edu/ bashforth/098_ PDF/06Sep15Connotation_Denotation.pdf [Accessed 27 Jun. 2019]. 